\title{
Finding Food Security through Changing the Agricultural Model to Sustain Insect Biodiversity
}

\author{
Astrid Jankielsohn \\ ARC-Small Grain, Bethlehem, South Africa \\ Email: jankielsohna@arc.agric.za
}

How to cite this paper: Jankielsohn, A. (2021) Finding Food Security through Changing the Agricultural Model to Sustain Insect Biodiversity. Advances in Entomology, 9, 122-130.

https://doi.org/10.4236/ae.2021.93011

Received: January 26, 2021

Accepted: July 13, 2021

Published: July 16, 2021

Copyright ( 2021 by author(s) and Scientific Research Publishing Inc. This work is licensed under the Creative Commons Attribution International License (CC BY 4.0).

http://creativecommons.org/licenses/by/4.0/

\section{(c) (i) Open Access}

\begin{abstract}
Worldwide biodiversity is being threatened by human activities to a greater level wherein the natural ecosystems are reaching the verge of collapsing. We are faced with four major interrelated challenges namely a changing climate, biodiversity loss, human population growth and food production for this growing population. Agricultural intensification contributes significantly to biodiversity loss. The agricultural model for our current food production systems is mainly based on the Green Revolution, which promoted the cultivation of crops in extensive monoculture fields and intensified external inputs of agrochemicals. This model resulted in biodiversity loss, particularly in insect populations. A model based on ecological intensification as an alternative to agricultural intensification with minimized use of agro-inputs may slow the rate of biodiversity loss resulting in more sustainable agricultural ecosystems.
\end{abstract}

\section{Keywords}

Food Security, Agricultural Model, Biodiversity Loss, Climate Change, Ecological Intensification, Insects, Ecosystem Functioning,

Human Population Increase

\section{Introduction}

Current agricultural practices cause stress on ecosystems resulting in global ecosystem collapse because of existing food production practices. The recent 2019 UN-biodiversity report [1] states that human activities are severely threatening worldwide biodiversity, with a million species facing extinction within the next few decades. With the disappearance of these organisms, our survival is threat- 
ened, because we rely on them for food production and a stable climate. We are presently facing four major interrelated challenges regarding change in climate, biodiversity loss, human population growth and food production. Changes in one of these challenges will ultimately have an impact on the others. This reflects the Gaia hypotheses, which proposes that the biosphere and the physical components of the Earth are closely incorporated to form a complex interacting system that maintains the climatic and biogeochemical conditions on earth in ideal homeostasis [2]. Human population growth has necessitated increased food production, which has disrupted this homeostasis and not only contributed significantly to change in climate, but also significantly affected biodiversity. Bradshaw et al. [3] showed that major changes in the biosphere are related to the increase in manmade systems, while Leclere et al. [4] believe that feeding the growing human population will oppose the ability to address the deterioration in biodiversity. Habitat conversion poses a significant threat to biodiversity [5] and the resulting pressure on natural ecosystems results in systems with deteriorating functionality. Agricultural intensification contributes significantly to population declines in taxa such as birds, insectivorous mammals and insects [6] as a result of management intensification, and use of chemicals [7]. Furthermore, the fertilizer used annually to maintain global food production has a considerable effect on the increase of greenhouse gas emissions, consequently affecting a change in climate [8], which in turn affects the functionality of ecosystems. Traditional farming methods demonstrated support of higher biodiversity, but these small-scale systems have been replaced by intensive, large-scale, monoculture cultivated areas [9]. Agricultural intensification does not necessarily contribute to a significant increase in productivity. UNCCD [10] pointed out that close to a fifth of the earth's vegetated land surface experienced a decline in productivity from 1998 to 2013, while the number of undernourished people in the world has also been increasing since 2014, reaching an estimated 815 million in 2016 [11]. Since the current agricultural model is not adequately feeding the global human population, while contributing to climate change, biodiversity loss and decline in land productivity, this model needs to be revisited in favor of a more sustainable model.

\section{The Model on Which Our Food Production Was Build}

Humans left their life of hunting and gathering behind and began to domesticate plants and animals in different parts of the world around 11,000 years ago. This was the beginning of agriculture and the design of the agricultural model that we know today [12], which resulted in $70 \%$ of the Earth's land surface being altered by humans [13]. Agriculture enabled the feeding of more people that ultimately supported the human population increase, which necessitated intensification of agriculture up to a point where the mid- $20^{\text {th }}$ century brought agricultural transformation in the form of the Green Revolution. The model of the Green Revolution was adopted globally and is based on cultivating crops in extensive mono- 
culture fields with increased external inputs of agrochemicals [14]. This model affected the agroecosystems resulting in the loss of diverse communities which sustained the biological functions essential in ecosystems. These essential biological functions were consequently replaced with increased external inputs of energy and agrochemicals [15]. The problem of decreased plant productivity, resulting from the loss of ecosystem functions, was solved by breeding improved cultivars [16], extensive soil tilling, improved irrigation, and the amplified use of inorganic fertilizer, chemical herbicides, pesticides and fungicides [17]. The intensification of mainly wheat, rice, and maize cropping systems sustained human populations during the past three decades [16], with the industrialized agricultural model enabling the development of a complex global food business that supplied sufficient food to billions of people [8]. These were, however, only temporary solutions and this industrialized model was accompanied by a very high price. The systems resulting from this model of agriculture are essentially open systems, with deteriorated diversity, where energy is lost from the systems. This necessitates regular and heavy external inputs to keep them functional. Walker [18] states that industrial agriculture turns oil into food, while Tubiello [19] views these systems as energy intensive. The current model of agricultural intensification is not sustainable and ineffective at feeding the world, while being harmful to the environment, and contributes to biodiversity loss.

\section{Changing the Model}

We will not realize food security if we continue building on the agricultural model developed by the Green Revolution, based on the idea that agricultural intensification will achieve the persistent goal of meeting global food demand. The present conventional cropping systems have a detrimental effect on natural ecosystems [20]; [21] and with widespread environmental impacts driven by conventional intensification of agriculture, a need has arisen to change to farming systems that will ensure food security, as well as protect the ecosystem services on which agriculture depends [22]. An interpretation of the 2050 Vision of the convention on biological diversity requires an urgent adoption of a conservation plan that retains the remaining biodiversity and restores degraded areas [4].

Leclere et al. [4] believe that biodiversity conservation will conflict with other societal demands from land, unless this transformation includes sustainable food production and consumption. Ecological intensification is based on intensive and smart use of natural resources and ecosystem functions to produce food sustainably without impacting on natural ecosystems. There is no single general model of ecological intensification, but this model may include diverse practices such as agroecology, organic agriculture, diversified farming systems, nature mimicry, conservation agriculture and agroforestry [23]. All of these production practices will have a constructive effect on the protection and maintenance of biodiversity in crop ecosystems. Stavi et al. [20] also believe that the moderate- 
intensity and integrated farming systems that lie between the two extremes of conventional and conservation agricultural systems will provide satisfactory conditions for crop production, while still sufficiently sustaining natural habitats. Functional biodiversity will influence the level and quality of ecosystem services to crops with organisms providing diverse ecosystem services such as biocontrol, pollination, and decomposition, which are key components in sustainable agricultural production [24]. Ecological intensification is characterized by increase of species diversity, together with functional diversity, and the resulting functional interactions within ecosystems [25]. Higher diversity will facilitate resilient systems able to withstand and recover from external shocks caused by environmental fluctuations. Rossing et al. [26] believe that organic and agro-ecological farming systems may better facilitate effective climate change relevant ecosystem services (carbon sequestration, energy use efficiency, soil water holding capacity, resilience to drought and resilience to hurricanes and heavy rainfall) than conventional systems. Systems built on the model of ecological intensification are diverse and are essentially closed systems. This implies that no or very little energy is lost from the system and everything is recycled and used within the system. The system will therefore require no or very little external inputs, rendering it sustainable. The diversity in the system will ensure adequate ecosystem services during environmental fluctuations and this system is flexible enough to adapt to climate and environmental change.

Ecological intensification may be the answer to sustainable food production and food security, provided it is combined with a drastic limit to human population growth and the population growth of the few domesticated species of animals and plants that humanity rely on for food. Domesticated animals have a significant effect on climate change and decline in biodiversity. While food production, in general, is responsible for about $25 \%$ of global greenhouse-gas emissions [27], within the agricultural sector, livestock farming has the largest environmental footprint [28]. Instead of trying to match food production to the growing human population by intensifying agriculture, we need to limit human population growth to stay within the limits of existing food production, biodiversity and climate change challenges. For optimal survival of a species, all species produce more offspring that can survive to adulthood. This survival rate is, however, influenced by environmental boundaries and limited by the availability of requirements for living, mainly space and food [29]. The human species is extremely successful and human population growth has extended these environmental and ecological boundaries to a point where the systems supporting life is on the verge of collapse. According to Bradshaw et al. [3] the impact of continued population growth, combined with uneven distribution of resources, leads to massive food insecurity. The solution would be to apply a strict population policy on a global scale. If we can achieve a reduction in family size of only half a child less per family, there will be a decrease of more than 3 billion people by $2100[30]$. 


\section{Including Insects in the Transformed Agricultural Model}

Historically insects were perceived as competitors, rather than allies in the race for survival. Biodiversity decline is more severe for invertebrates than for vertebrates, with dramatic rates of decline in insects that may lead to the extinction of $40 \%$ of the world's insect species over the next few decades [6]. Insects are affected more severely by agricultural intensification than vertebrates and plants [31]. Various reports warn of declines extending broadly across arthropod lineages, causing decrease in numbers instead of individual species, resulting in losses that could result in deterioration of trophic webs [32] [33] [34] [35]. If this continues, it will result in the eventual collapse of ecosystems and our ability to produce food since insects are at the structural and functional base of many of the world's ecosystems [6]. The best-documented and most interpretable insect declines come from areas of high human occupation, areas of intensive agriculture, and areas where wet forests are experiencing desiccating conditions due to climate change [31]. Habitat loss and fragmentation are probably the most serious threats to insect populations, resulting in reduced and homogeneous assemblages of generalist species [36]. These generalist species cannot perform the diverse ecological functions required to ensure appropriate functioning of ecosystems. Insect ecologist Prof E.O. Wilson warned that “...mass insect extinction could mean no more nematodes and other worms moving soil around, and bees and other pollinators aiding plant reproduction. Agricultural yields would drop, bringing starvation, war and an 'ecological dark age' [37]."At this juncture the world cannot afford to continue to ignore these warnings.

Insects make up the greater part of terrestrial diversity [38] and are fundamental elements for adequate ecosystem functioning, such as ecosystem cycling, pollination, predation/parasitism, and decomposition. In agricultural ecosystems these ecosystem functions, provided by insects, were replaced with external inputs such as chemical fertilizers and synthetic pesticides. There are two major causes of biodiversity loss in insect populations namely habitat destruction and use of agro-chemicals. The collective impacts of many modern farming practices are highly detrimental to biodiversity in general, and insects in particular [31]. Insect habitats are destroyed by the adoption of conversion of agro-ecosyems into large scale monocropping systems. Suitability of habitats for the survival of insect populations depends on two factors, availability of sufficient food sources and adequate shelter against adverse conditions for the particular insect population. Crop monoculture plantations create ideal habitats for a limited number of generalist insect species by providing an endless source of food and shelter. These monoculture practices, however, exclude the majority of other specialist insect species from this system due to decrease in a diversity of suitable habitats. In the absence of competition and predation, the population growth of this limited number of species escalates, enabling high dominance of these insect populations. Attempts to control these dominant insect species on crops, by using chemical pesticides, cause further damage to other insect populations while the 
dominant insect populations develop resistance against these chemicals and continue to increase. Dudley and Alexander [7] regard chemical pesticides as the major cause of insect losses in recent times, while application of chemical pesticides does not contribute significantly to an increase in crop yields, but as a result of pest resistance can even lower yields and subsequent profit [39]. A more effective way to prevent dominant insect pest populations from reaching levels where major crop damage occur would be to manage the system in such a way that diverse habitats, accommodating increased insect diversity that are being preserved, instead of increasing the dominance of one or two species. This can be achieved with inter-cropping, crop rotation, planting of cover crops and the protection of "green areas" on the farm. Wagner [31] concluded that any efforts to make agricultural practices more sustainable and biodiversity friendly would have great dividends for insects and all the ecosystem processes that depend on them.

\section{Conclusion}

Immediate actions are necessary to address the four challenges in agriculture, climate change, biodiversity loss (especially in insect populations), human population growth and food production. The most effective way to address these challenges would be to revise the existing agricultural model and adapt it to one based on habitat restoration and reduction in agrochemical inputs, while keeping the human population growth within ecological boundaries. By protecting and sustaining biodiversity, the ecosystem functions provided by diverse populations would strengthen ecosystems, facilitate sustainable food production, and mitigate some of the effects of climate change. To ensure the successful implementation of this adapted model, collaboration across diverse sectors, that will include farmers, industry partners, scientists, educators, and politicians, will be crucial. The sharing of information, with total transparency, between collaborators will be vital for the successful implementation of the adapted model.

\section{Conflicts of Interest}

The author declared that there is no conflict of interest.

\section{References}

[1] Food and Agriculture Organization (FAO) (2019) The State of the World's Biodiversity for Food and Agriculture. FAO Commission on Genetic Resources for Food and Agriculture Assessments, Rome, $572 \mathrm{p}$. http://www.fao.org/3/CA3129EN/CA3129EN.pdf

[2] Lovelock, J. (2001) Homage to Gaia: The Life of an Independent Scientist. Oxford University Press, Oxford.

[3] Bradshaw, C.J.A., Ehrlich, P.R., Beattie, A., Ceballos, G., Crist, E., Diamond, J., Dirzo, R., Ehrlich, A.H., Harte, J., Harte, M.E., Pyke, G., Raven, P.H., Ripple, W.J., Saltre, F., Turnbull, C., Wackernagel, M. and Blumstein, D.T. (2021) Underestimating the Challenges of Avoiding a Ghastly Future. Frontiers in Conservation Science, 1, Article ID: 615419. https://doi.org/10.3389/fcosc.2020.615419 
[4] Leclere, D., Obersteiner, M., Barrett, M., et al. (2020) Bending the Curve of Terrestrial Biodiversity Needs an Integrated Strategy. Nature, 585, 552-556.

[5] Maxwell, S.L., Fuller, R.A., Brooks, T.M. and Watson, J.E.M. (2016) Biodiversity: The Ravages of Guns, Nets, and Bulldozers. Nature, 536, 143-145. https://doi.org/10.1038/536143a

[6] Sánchez-Bayo, F. and Wyckhuys, K.A.G. (2019) Worldwide Decline of the Entomofauna: A Review of Its Drivers. Biological Conservation, 232, 8-27. https://www.elsevier.com/locate/biocon https://doi.org/10.1016/j.biocon.2019.01.020

[7] Dudley, N. and Alexander, S. (2017) Agriculture and Biodiversity: A Review. Biodiversity, 18, 45-49. https://doi.org/10.1080/14888386.2017.1351892

[8] Horton, P. (2017) We Need Radical Change in How We Produce and Consume Food. Food Security, 9, 1323-1327. https://doi.org/10.1007/s12571-017-0740-9

[9] Rudel, T., De Fries, R., Asner, G.P. and Laurance, W.F. (2009) Changing Drivers of Deforestation and New Opportunities for Conservation. Conservation Biology, 23, 1396-1405. https://doi.org/10.1111/j.1523-1739.2009.01332.x

[10] UNCCD (2017) Global Land Outlook. UN Convention to Combat Desertification, Bonn.

[11] Food and Agriculture Organization (FAO) (2017) How Close Are We to \#ZeroHunger? FAO, Rome.

[12] Diamond, J. (1999) The Worst Mistake in the History of the Human Race. https://www.discovermagazine.com/planet-earth/the-worst-mistake-in-the-historyof-the-human-race

[13] IPBES (2019) Global Assessment Report on Biodiversity and Ecosystem Services. IPBES Secretariat, Paris.

[14] Garibaldi, L.A., Gemmill-Herren, B., D’Annolfo, R., Graeub, B.E., Cunningham, S.A. and Breeze, T.D. (2017) Farming Approaches for Greater Biodiversity, Livelihoods, and Food Security. Trends in Ecology \& Evolution, 32, 68-80. https://doi.org/10.1016/j.tree.2016.10.001

[15] Bommarco, R., Kleijn, D. and Potts, S.G. (2012) Ecological Intensification: Harnessing Ecosystem Services for Food Security. Trends in Ecology \& Evolution, 28, 230-238. https://doi.org/10.1016/j.tree.2012.10.012

[16] Cassman, K.G. (1999) Ecological Intensification of Cereal Production Systems: Yield Potential, Soil Quality, and Precision Agriculture. PNAS, 96, 5952-5959.

https://www.pnas.org/content/pnas/96/11/5952.full.pdf https://doi.org/10.1073/pnas.96.11.5952

[17] Tilman, D., et al. (2001) Forecasting Agriculturally Driven Global Environmental Change. Science, 292, 281-284. https://doi.org/10.1073/pnas.96.11.5952

[18] Walker, D.A. (2009) Biofuels, Facts, Fantasy, and Feasibility. Journal of Applied Phycology, 21, 509-517. https://doi.org/10.1007/s10811-009-9446-5

[19] Tubiello, F.N., et al. (2015) The Contribution of Agriculture, Forestry and Other Land Use Activities to Global Warming, 1990-2012. Global Change Biology, 21, 2655-2660. https://doi.org/10.1007/s10811-009-9446-5

[20] Stavi, I., Golan, B. and Zaady, E. (2016) Soil Functions and Ecosystem Services in Conventional, Conservation, and Integrated Agricultural Systems. A Review. Agronomy for Sustainable Development, 36, 32.

https://doi.org/10.1007/s13593-016-0368-8 
[21] Duru, M., Therond, O., Martin, G., Martin-Clouaire, R., Magne, M.A., Justes, E., Journet, E.P., Aubertot, J.N., Savary, S., Bergez, J.E. and Sarthou, J.P. (2015) How to Implement Biodiversity-Based Agriculture to Enhance Ecosystem Services: A Review. Agronomy for Sustainable Development, 35, 1259-1281. https://doi.org/10.1007/s13593-015-0306-1

[22] Garnett, T., et al. (2013) Sustainable Intensification in Agriculture: Premises and Policies. Science, 341, 33-34. https://doi.org/10.1126/science.1234485

[23] Tittonell, P. (2014) Ecological Intensification of Agriculture-Sustainable by Nature. Current Opinion in Environmental Sustainability, 8, 53-61.

https://www.sciencedirect.com https://doi.org/10.1016/j.cosust.2014.08.006

[24] Hokkanen, H.M.T. and Menzler-Hokkanen, I. (2018) Urgent Need to Develop Ecostacking Techniques to Enhance Ecosystem Services in Cropping Systems. ArthropodPlant Interactions, 12, 477-482. https://doi.org/10.1007/s11829-018-9620-2

[25] Tscharntke, T., Klein, A.M., Kruess, A., Steffan-Dewenter, I. and Thies, C. (2005) Landscape Perspectives on Agricultural Intensification and Biodiversity: Ecosystem Service Management. Ecology Letters, 8, 857-874. https://doi.org/10.1111/j.1461-0248.2005.00782.x

[26] Rossing, W.A.H., Modernel, P. and Tittonell, P. (2013) Diversity in Organic and Agro-Ecological Farming Systems for Mitigation of Climate Change Impact, with Examples from Latin America. In: Fuhrer, J. and Gregory, P.J., Eds., Climate Change Impact and Adaptation in Agricultural Systems, CAB International, Wallingford, 69-87. https://doi.org/10.1079/9781780642895.0069

[27] Vermeulen, S.J., Campbell, B.M. and Ingram, J.S.L. (2012) Climate Change and Food Systems. Annual Review of Environment and Resources, 37, 195-222. https://doi.org/10.1146/annurev-environ-020411-130608

[28] Steinfeld, H. (2006) Livestock's Long Shadow: Environmental Issues and Options. FAO, Rome.

[29] Markert, C.L. (1966) Biological Limits on Population Growth. BioScience, 16, 859-862. https://doi.org/10.2307/1293665

[30] United Nations DESA/Population Division (2017) World Population Prospects 2019. https://population.un.org/wpp

[31] Wagner, D.L. (2020) Insect Declines in the Anthropocene. Annual Review of Entomology, 65, 457-480. https://doi.org/10.1146/annurev-ento-011019-025151

[32] Conrad, K.F., Warren, M.S., Fox, R., Parsons, M.S. and Woiwod, I.P. (2006) Rapid Declines of Common, Widespread British Moths Provide Evidence of an Insect Biodiversity Crisis. Biological Conservation, 132, 279-291. https://doi.org/10.1016/j.biocon.2006.04.020

[33] Dirzo, R., Young, H.S., Galetti, M., Ceballos, G., Isaac, N.J.B. and Collen, B. (2014) Defaunation in the Anthropocene. Science, 345, 401-406.

https://doi.org/10.1126/science.1251817

[34] Gaston, K.J., \& Fuller, R.A. (2008) Commonness, Population Depletion and Conservation Biology. Trends in Ecology \& Evolution, 23, 14-19.

https://doi.org/10.1016/j.tree.2007.11.001

[35] Winfree, R.W., Reilly, J.R., Bartomeus, I., Cariveau, D.P., Williams, N.M., et al. (2018) Species Turnover Promotes the Importance of Bee Diversity for Crop Pollination at Regional Scales. Science, 359, 791-793.

https://doi.org/10.1126/science.aao2117 
[36] Newbold, T., Hudson, L.N., Contu, S., Hill, S.L.L., Beck, J., Liu Y., et al. (2018) Widespread Winners and Narrow-Ranged Losers: Land Use Homogenizes Biodiversity in Local Assemblages Worldwide. PLOS Biology, 16, e2006841.

https://doi.org/10.1371/journal.pbio.2006841

[37] (2007) Wilson: Insects Essential to Human Life.

https://phys.org/news/2007-07-wilson-insects-essential-human-life.html

[38] Stork, N.E. (2018) How Many Species of Insects and Other Terrestrial Arthropods Are There on Earth? Annual Review of Entomology, 63, 31-45. https://doi.org/10.1146/annurev-ento-020117-043348

[39] Bredeson, M.M. and Lundgren, J.G. (2018) Thiamethoxam Seed Treatments Have No Impact on Pest Numbers or Yield in Cultivated Sunflowers. Journal of Economic Entomology, 108, 2665-2671. https://doi.org/10.1093/jee/tov249 